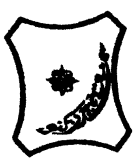

Bayero Journal of Pure and Applied Sciences, 12(2): 49 - 56

Received: July, 2019

Accepted: November, 2019

ISSN $2006-6996$

\title{
CENTRAL COMPOSITE DESIGN OPTIMIZATION OF COPPER (II) IONS REMOVAL IN AQUEOUS SOLUTION USING Azadirachta indica (Neem) LEAF POWDER
}

\author{
Sulaiman, M. S. \\ Department of Pure and Industrial chemistry, Bayero University Kano, P.M.B 3011, Kano Nigeria \\ *Corresponding author: sdanguguwa@gmail.com
}

\begin{abstract}
Biosorption is considered as a potential method for the removal of heavy toxic metals from waste solution and as alternative to other conventional process such as precipitation, ion exchange, electrochemical treatment and evaporative recovery, especially, when the concentration of the heavy metal ion is low. In the present study, (Azadirachta indica) neem leaves Powder (NLP), was investigated for the removal of Cu(II) ions from aqueous solution based on modelling and optimization. Central composite design was successfully applied to develop a response surface to optimize medium conditions. Characterisations of the NLP was conducted, and the effects of contact time (0-180 minutes), Cu(II) ion concentration (10-50 mg/L), temperature (298-318 $\mathrm{K})$ and dosage $(0.5-2.5 \mathrm{~g} / \mathrm{L})$ were studied in batch process. The optimal adsorption of copper obtained were found to be $308 \mathrm{~K}, 97.5 \mathrm{~min}$ and $1.5 \mathrm{~g}$ respectively resulting in $100 \%$ of adsorption of copper The analysis with FTIR indicated that possible hydroxyl and carboxyl functional groups are involved in metal Cu(II) ions biosorption. Adsorption isotherms were modelled by the Langmuir and Freundlich isotherm equations, with the former providing a better fit for the data. Results obtained from this study indicate that NLP is a very promising candidate for the low-cost and high-capacity removal of $\mathrm{Cu}(\mathrm{II})$ ions from aqueous solution.

Keywords: Biosorption, Neem, Copper (II), Response surface methodology and Central composite design.
\end{abstract}

\section{INTRODUCTION}

Heavy metals pollution have been a major concern globally, due to their toxicity, bioaccumulation tendency and persistency in nature (Das, 2017) and in order to protect public health, they have to be eliminated from the environment (Chafik, et. al., 2014).

Even though copper has been known to be among the most common toxic heavy metals (Das, 2017), but still plays a vital role in human health as the element is needed in the metabolism of lipids, carbohydrates and even in proper functioning of the heart and blood vessels (Gupta et. al., 2006).

According to international regulation, the concentration limit of copper in water and waste water is $1 \mathrm{mg} / \mathrm{L}$ (Ayhan and Ozacar, 2008). Excess amount of copper can cause a substantial health hazard as damage to kidney, liver, pancreas and damage human psychology. The major industries discharging copper into the waste stream include fertilizer industries, battery industries, pulp and paper copper polishing and electroplating (Ozturk and Shan, 2015).
In view of that, copper concentration in the waste stream has to be reduced to an acceptable environmental regulation.

Various processes, including chemical precipitation, ion exchange, ultra-filtration, reverse osmosis, electroplating and adsorption are applied in the process of heavy metals removal. Of these, adsorption using activated carbon has been the most widely used due to higher efficiency and easy operation (Ozturk and Shan, 2015) However, adsorption onto activated carbon is expensive and may require additional chemicals to improve efficiency This leads to the searching of a cost effective and efficient method for the removal of heavy metals from waste stream (Qi and Aldrich, 2008). Biosorption has recently attracted considerable amount of attention as alternative method used for the removal and recovery of toxic metals present in waste effluents compared to other conventional technologies due to numerous advantages such as low sludge production, low investment and operational cost and above all higher efficiency (Krishnani et al., 2008). 
BAJOPAS Volume 12 Number 2, December, 2019

Copper metal removal by biosorption has so far been investigated using different biosorbents Veglio and Beolchini, (1997), such as teak leaves (Rathnakumar et al., 2009). Palmaria palmate and brewery waste (Yang et al., 2011). Green algae (Gupta et al, 2006). Fish scales (Huang, 2007), wheat shell (Basci et al, 2004). Thiobacillus ferrooxidans (Hossain and Anantharaman, 2005). Penicillium cyclopium (lanis et al, 2006) and spent tea leaves (Bajpai and Jain, (2010).

The conventional method of optimizing the process variables are expensive, difficult and time consuming as it needs a large number of experimental runs, therefore, response surface methodology technique reduces the number of experiments and provides appropriate model for process optimization (Singh et. al., 2017).

The objective of the present study were to examine the adsorption potential of neem leaves for copper II ions removal from aqueous solution in batch mode, and focus on the application of statistical approach to see interactive effects of combine variables on complex adsorption process using central composite design.

\section{MATERIALS AND METHODS}

\section{Biosorbent Collection and Preparation}

The neem leaves used in this study was collected fresh from a local tree at the Bayero university kano and identified at the department of plant biology. The leaves were washed severally and rinsed with deionised water to remove all impurities. Crispy dried leaves were obtained after drying at a temperature of about $60^{\circ} \mathrm{C}$ for 24 hours, and later ground and sieved to a particle size of about 45-62 ųm. The sieved materials were stored and labelled NLP.

\section{Synthetic Copper Solution}

Hydrated Copper(II) chloride was used as a source of copper stock solution. The preparation was done by dissolving appropriate amount of $99 \%$ hydrated copper (II) chloride with $1000 \mathrm{ml}$ of deionised water to form a standard stock solution of $100 \mathrm{mg} / \mathrm{L}$ of
Copper(II) solutions. Different concentration was later prepared by appropriate dilutions.

\section{Adsorbent characterization}

In order to understand the binding mechanism of copper(II) ions, Fourier infrared spectroscopy (FTIR) was used in determining the functional groups available in the neem leaves. The surface morphology was visualized using SEM coupled with EDX.

\section{Batch adsorption Experiment}

Batch adsorption of 30 experiments design by central composite design approach using response surface methodology where conducted by the NLP as an adsorbent to study the effect of contact time (0-180 minutes), copper concentration(10-50 $\mathrm{mg} / \mathrm{L})$, temperature (298-305K) and adsorbent dosage $(0.5-2.5 \mathrm{~g})$. The experiment was carried out in a $250 \mathrm{ml}$ conical flask placed in a water bath shaker. All the experiments were performed in duplicate and the average values were recorded.

The amount of copper (II) ions adsorbed $(\mathrm{mg} / \mathrm{g})$ was determined using the equation (1)

$$
q_{e=\frac{C_{o}-C_{e}}{M} \mathrm{~V}}
$$

Also the percentage removal of copper was computed as

$$
\text { (\%) Removal }=\frac{C_{o-} C_{e}}{C_{o}} \times 100
$$

Where $\mathrm{Co}$ and $\mathrm{Ce}$ are initial and final copper concentration, $V$ is the volume of the biosorbate and $M$ is the weight of the biosorbent.

\section{Design of Experiment and Optimization}

A standard response surface methodology design called central composite design, which is the most popular choice to fit second order model, (Ozturk, 2015) was applied in this work to study the variables of adsorption of $\mathrm{Cu}$ (II) ions from aqueous solution in a batch process.

Four process variables (Temperature, Concentration, Dosage and Contact time) were studied using the CCD models with the help of design-expert software (Version 6.0). The range of selected independent variables is presented in Table 1.

Table 1: Experimental factor levels used in the design.

\begin{tabular}{llll}
\hline Independent Variavble & Factor & Coded Levels & \\
\hline & & -1 & +1 \\
Dosage $(\mathrm{g})$ & $\mathrm{A}$ & 0.50 & 2.50 \\
Contact Time(Mins) & B & 15.00 & 180.00 \\
Concentratio(mg/L & $\mathrm{C}$ & 10.00 & 50.00 \\
Temprature (K) & $\mathrm{D}$ & 298.00 & 318.00 \\
\hline
\end{tabular}

In order to obtain the interactions between the processed variables and the response, the experimental data were evaluated with the design- expert including analysis of variance (ANOVA). The quality of the fit of the polynomial model was expressed by the coefficient of determination $\left(R^{2}\right)$ and the statistical significance was checked by the F- test. 
BAJOPAS Volume 12 Number 2, December, 2019

RESULTS AND DISCUSSION

Surface area of biosorbent (ASAP)

Generally the greater the surface area of a biosorbent, the greater the metal biosorption. Based on the Surface area and pore diameter (ASAP) analysis, the NLP surface area was found to be $2.3102 \mathrm{~m}^{2} / \mathrm{g}$. Which is higher than rubber leaves, $0.46 \mathrm{~m}^{2} / \mathrm{g}$ (Ngah and Hanafiah, 2008), Spirogyra spp., $1.31 \mathrm{~m}^{2} / \mathrm{g}$ (Gupta et al., 2006), rice bran, $0.46 \mathrm{~m}^{2} / \mathrm{g}$ (Montanher et al., 2005) and soya meal shell, $0.76 \mathrm{~m}^{2} / \mathrm{g}$ (Arami et al., 2006).and also lower than activated carbon, $1100 \mathrm{~m}^{2} / \mathrm{g}$ (Ozacar and Sengil, 2002), Moringa oliefera, $4.01 \mathrm{~m}^{2} / \mathrm{g}$ (Kumar et al., 2006) and Sargasssum $s p, 8.13 \mathrm{~m}^{2} / \mathrm{g}$ (Sheng et al., 2008).

Based on the conclusion of many researchers, surface area and pore sizes might be involved in the biosorption mechanism and since NLP does not have a highly porous structure, biosorption might occur through chemical sorption with the presence of functional groups and ion exchange (Sulaiman and Garba, 2014)

\section{Surface functional groups}

Different adsorption peaks displayed by the FTIR indicates the presence of various functional groups on the surface of the NLP before and after adsorption. Based on the attribution of peaks, it can be known that NLP contains different types of functional groups and different biosorption processes such as ion exchange, electrostatic attraction and complexation might be involved in the adsorption mechanism.

By comparing the fresh NLP and $\mathrm{Cu}$ (II) loaded NLP it can be observed that there are shift in some certain cases in wave number indicating metal binding process on the NLP. The relevance of a shift in the spectra is that there is an effect of metal adsorption on the functional groups (Yaziciet al., 2008). For the fresh NLP as shown in Figure 1 the spectra show a band of range 3862.04 to $595.09 \mathrm{~cm}^{-1}$. After $\mathrm{Cu}(\mathrm{II})$ ions biosorption the spectra changes from 3905.83 to $582.36 \mathrm{~cm}^{-1}$ as in Figure 2.

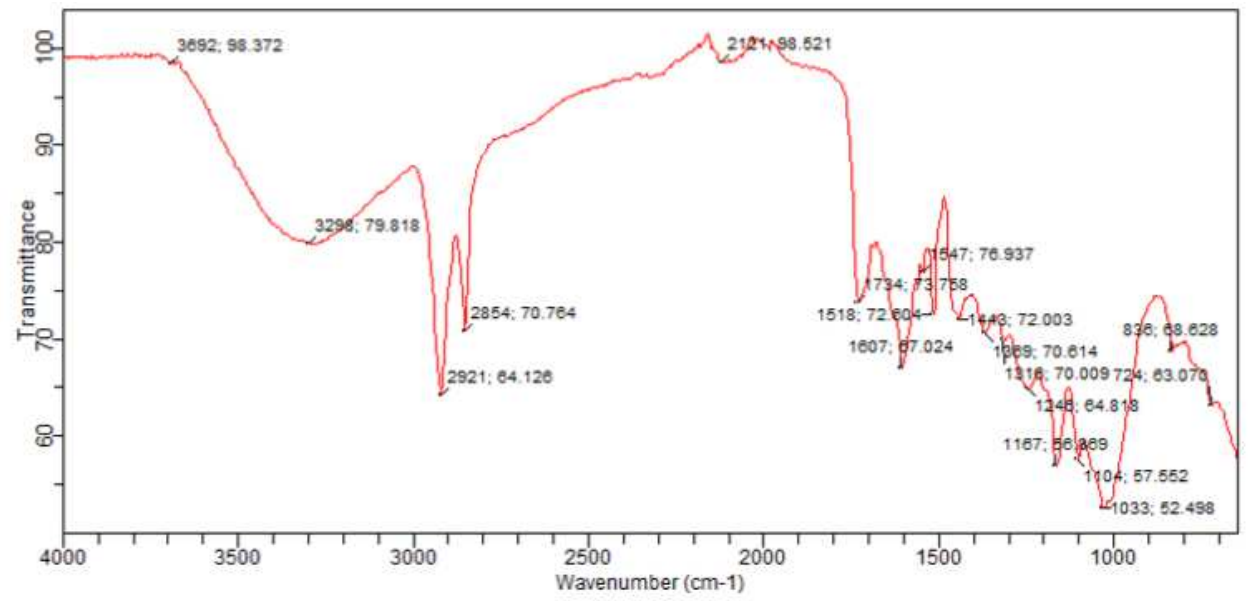

Fig 1: FTIR spectrum for NLP before adsorption

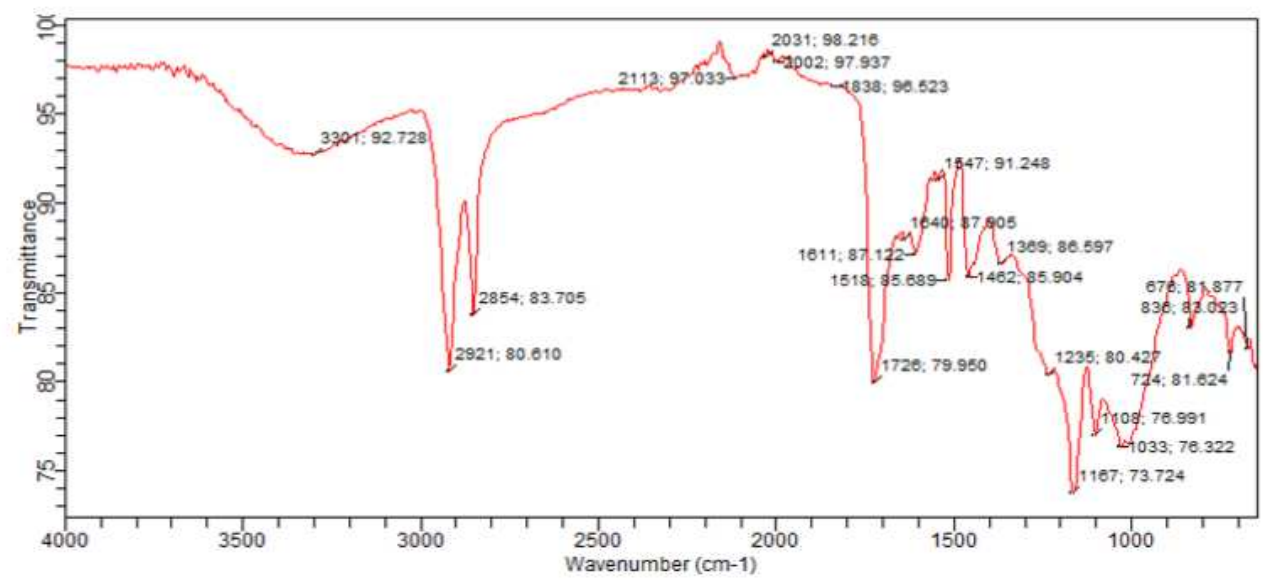

Fig 2: FTIR Spectrum of NLP after $\mathrm{Cu}(\mathrm{II})$ ions adsorption. 
BAJOPAS Volume 12 Number 2, December, 2019

\section{Surface Topography (SEM/EDX)}

SEM (Scanning electron microscope) and EDX (Energy-dispersive X-ray spectroscopy) are useful analytical equipment for evaluating the characteristics of adsorbent elements. Figure 3 showed the SEM-EDX results for NLP before $\mathrm{Cu}(\mathrm{II})$ ion adsorption. The SEM images showed that the NLP possess surface morphology with regular pore size which is helpful for $\mathrm{Cu}$ (II) ions biosorption, although the SEM results for the NLP before and after bisosorption looks almost the same, however, EDX results clearly indicate that NLP consist of mainly $\mathrm{C}$ and $\mathrm{O}$, and small amounts of, $\mathrm{Ca}, \mathrm{Mg}, \mathrm{K}, \mathrm{P}$ and $\mathrm{S}$.

While Figure 4 shows SEM and EDX for NLP after the biosorption on which $\mathrm{Cu}$ (II) ions was confirmed. From the SEM results, nonuniformed bright spots indicated $\mathrm{Cu}$ (II) ions presence, which signifies that not all the functional groups are responsible for $\mathrm{Cu}(\mathrm{II})$ ions adsorption from the solution. After the adsorption for the NLP, $\mathrm{Mg}$ and $\mathrm{K}$ are been replaced by $\mathrm{Cu}(\mathrm{II})$ peaks, this clearly indicates that ion-exchange might be one of the mechanisms for $\mathrm{Cu}$ (II) removal.
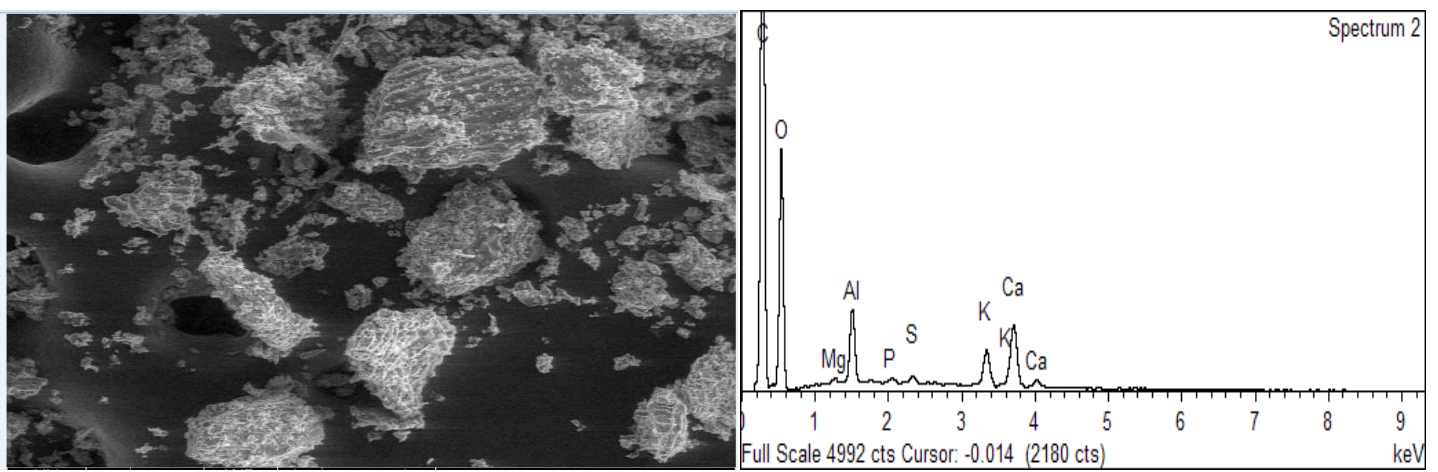

Figure 3: SEM and EDX images of NLP before Cu(II) ions Adsorption
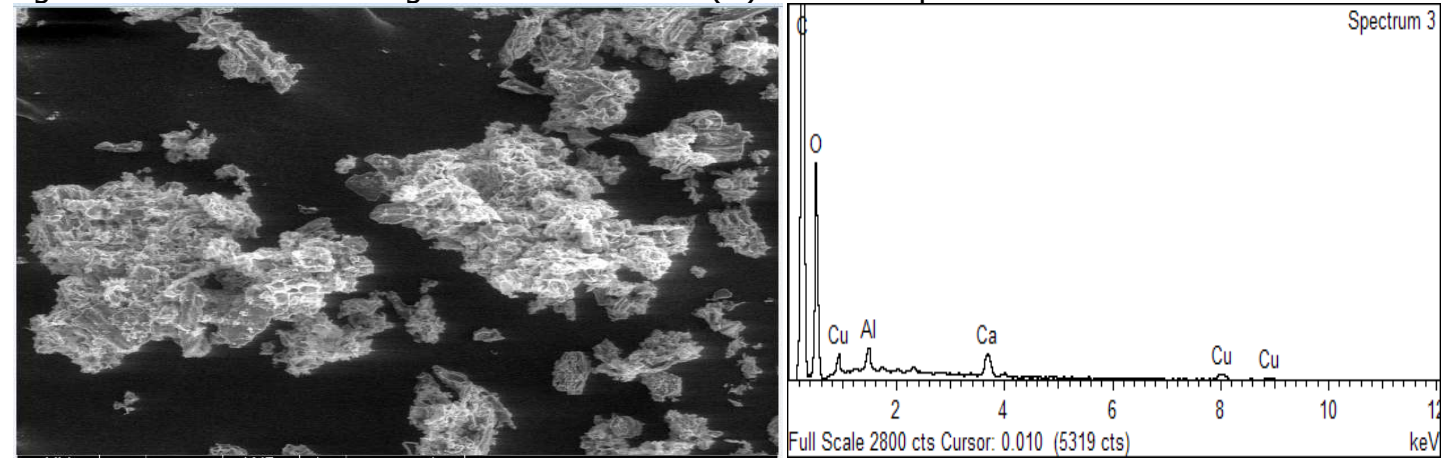

Figure 4: SEM and EDX images of NLP after Cu(II) ions Adsorption

\section{Evaluation of the model}

In order to ascertain the different model such as linear, 2FI, quadratic, evaluation was done on the basis of scores from the sequential model sum of squares. The result shows the quadratic model has a higher score. The larger magnitude of $F(9.50)$ and smaller value of $P$ $(0.0058)$ indicates that the quadratic model is highly significant and was found to be good.

Table 2: Sequential Model Sum of Squares

\begin{tabular}{lllllll}
\hline \multicolumn{1}{c}{ Source } & Sum of squares & $d f$ & Mean square & F-value & Prob $>F$ & \\
\hline Mean & $\underline{1529.38}$ & 1 & $\underline{1529.38}$ & & & \\
Block & 3.56 & 1 & 3.56 & & & \\
Linear & 5.90 & 4 & 1.47 & 0.54 & 0.7102 & \\
2FI & 17.55 & 6 & 2.93 & 1.09 & 0.4061 & \\
Quadratic & $\underline{30.12}$ & 4 & $\underline{7.53}$ & $\underline{5.77}$ & $\underline{0.0058}$ & Suggested \\
Cubic & 1.34 & 8 & 2.12 & 9.50 & 0.0066 & Aliased \\
Residual & 1.34 & 6 & 0.22 & & & \\
Total & 1604.77 & 30 & 53.49 & & & \\
\hline
\end{tabular}


BAJOPAS Volume 12 Number 2, December, 2019

Quadratic model for copper (II) adsorption process

To examine the combine effect of four different independent process parameters on percentage

removal of copper (II) ion, 30 experiments were performed. The experimental designed is given $\mathrm{n}$ the Table 3 along with the experimental data and the predicted responses;

Table 3: CDD Experimental Designed Factors

\begin{tabular}{|c|c|c|c|c|c|c|}
\hline Run & $\begin{array}{c}\text { Dosage } \\
\text { (g) }\end{array}$ & $\begin{array}{c}\text { Contact } \\
\text { Time } \\
\text { (Mins) }\end{array}$ & $\begin{array}{c}\text { Concentration } \\
(\mathrm{mg} / \mathrm{L})\end{array}$ & $\begin{array}{c}\text { Temperature } \\
\text { (K) }\end{array}$ & $\begin{array}{l}\text { Predicted } \\
\text { Value }\end{array}$ & $\begin{array}{c}\text { Actual } \\
\text { Value }\end{array}$ \\
\hline 1 & 2.5 & 180 & 10 & 298 & 8.71 & 8.08 \\
\hline 2 & 2.5 & 15 & 50 & 318 & 7.64 & 6.43 \\
\hline 3 & 0.5 & 180 & 10 & 298 & 8.22 & 8.27 \\
\hline 4 & 2.5 & 180 & 50 & 298 & 9.03 & 8.31 \\
\hline 5 & 1.5 & 97.5 & 30 & 308 & 6.89 & 7.53 \\
\hline 6 & 2.5 & 180 & 50 & 318 & 8.07 & 8.17 \\
\hline 7 & 1.5 & 97.5 & 30 & 308 & 7.10 & 5.87 \\
\hline 8 & 2.5 & 180 & 10 & 318 & 8.12 & 8.20 \\
\hline 9 & 2.5 & 15 & 10 & 318 & 6.67 & 7.04 \\
\hline 10 & 2.5 & 15 & 10 & 298 & 2.88 & 3.90 \\
\hline 11 & 2.5 & 15 & 50 & 298 & 8.39 & 8.08 \\
\hline 12 & 1.5 & 97.5 & 30 & 308 & 6.81 & 6.62 \\
\hline 13 & 0.5 & 15 & 50 & 298 & 7.75 & 8.25 \\
\hline 14 & 0.5 & 15 & 10 & 298 & 6.99 & 7.40 \\
\hline 15 & 0.5 & 180 & 10 & 318 & 5.77 & 7.44 \\
\hline 16 & 1.5 & 97.5 & 30 & 308 & 7.85 & 8.27 \\
\hline 17 & 0.5 & 15 & 50 & 318 & 5.26 & 5.02 \\
\hline 18 & 0.5 & 180 & 50 & 318 & 5.26 & 5.02 \\
\hline 19 & 0.5 & 15 & 10 & 318 & 5.26 & 5.02 \\
\hline 20 & 0.5 & 180 & 50 & 298 & 5.26 & 5.02 \\
\hline 21 & 0.5 & 97.5 & 30 & 308 & 9.35 & 8.94 \\
\hline 22 & 1.5 & 67.5 & 30 & 308 & 7.96 & 8.12 \\
\hline 23 & 1.5 & 262.5 & 30 & 308 & 8.93 & 8.45 \\
\hline 24 & 15 & 97.5 & 70 & 308 & 9.27 & 9.51 \\
\hline 25 & 1.5 & 97.5 & 30 & 308 & 6.01 & 6.95 \\
\hline 26 & 1.5 & 97.5 & 30 & 328 & 9.22 & 8.04 \\
\hline 27 & 1.5 & 97.5 & 10 & 308 & 6.28 & 7.86 \\
\hline 28 & 1.5 & 97.5 & 30 & 288 & 8.72 & 6.90 \\
\hline 29 & 3.5 & 97.5 & 30 & 308 & 5.26 & 5.75 \\
\hline 30 & 1.5 & 97.5 & 30 & 308 & 5.26 & 5.75 \\
\hline
\end{tabular}

The second order polynomial equation developed represents responses as a function of adsorbent Dosage (A), contact time (B), initial concentration (C) and temperature (D).

An empirical relationship between the response and input test variable in coded units can be express by the following equation.

$\boldsymbol{S q r t}(\boldsymbol{P e r c e n t a g e})=+5.38-0.20 * A+0.27 * B+0.27 * C-0.24 * D+0.70 * A^{2}+0.81 * B^{2}+$ $0.44 * C^{2}+0.41 * D^{2}+0.42 * A * B+0.57 * A * C-0.37 * A * D-0.46 * B * C+0.21 * B * D+$ $0.44 * C * D$

(3)

The above equation describe how copper (II) adsorb onto NLP was affected by individual variables. Negative coefficient value indicated that individual or double interaction factor negatively affect copper (II) adsorption, while positive coefficient value represent the factor increases copper (II) percentage.
Among all linear factors studied, adsorbent dosage had a negative effect while contact time, initial concentration and temperature had a positive effect on copper (II) removal.

The adequency and significance of the quadratic model was justified by the analysis of variance (ANOVA) as shown in the Table 4. 
BAJOPAS Volume 12 Number 2, December, 2019

Table 4: Analysis of Variance Table

\begin{tabular}{ccccccc}
\hline Source & Sum of Squares & $D F$ & Mean Square & F Value & Prob $>F$ & \\
\hline Block & 3.56 & 1 & $\mathbf{3 . 5 6}$ & & & Significant \\
Model & 53.57 & $\mathbf{1 4}$ & $\mathbf{3 . 8 3}$ & 2.93 & 0.0266 & \\
A & $\mathbf{1 . 0 0}$ & $\mathbf{1}$ & $\mathbf{1 . 0 0}$ & 0.77 & 0.3953 & \\
B & $\mathbf{1 . 6 9}$ & $\mathbf{1}$ & $\mathbf{1 . 6 9}$ & 1.30 & 0.2737 & \\
C & $\mathbf{1 . 8 1}$ & $\mathbf{1}$ & $\mathbf{1 . 8 1}$ & 1.38 & 0.2589 & \\
D & $\mathbf{1 . 4 0}$ & $\mathbf{1}$ & $\mathbf{1 . 4 0}$ & 1.07 & 0.3186 & \\
$A^{2}$ & $\mathbf{1 3 . 2 5}$ & $\mathbf{1}$ & $\mathbf{1 3 . 2 5}$ & 10.16 & 0.0066 & \\
$B^{2}$ & 17.90 & $\mathbf{1}$ & 17.90 & 13.73 & 0.0024 & \\
$C^{2}$ & 5.21 & $\mathbf{1}$ & 5.21 & 3.99 & 0.0654 & \\
$D^{2}$ & 4.55 & $\mathbf{1}$ & 4.55 & 3.49 & 0.0829 & \\
$A B$ & 2.86 & $\mathbf{1}$ & 2.86 & 2.19 & 0.1610 & \\
$A C$ & 5.24 & $\mathbf{1}$ & 5.24 & 4.02 & 0.0647 & \\
$A D$ & 2.23 & $\mathbf{1}$ & 2.23 & 1.71 & 0.2118 & \\
$B C$ & 3.42 & $\mathbf{1}$ & 3.42 & 2.62 & 0.1278 & \\
$B D$ & 0.71 & $\mathbf{1}$ & 0.71 & 0.55 & 0.4721 & \\
$C D$ & 3.09 & $\mathbf{1}$ & 3.09 & 2.37 & 0.1459 & \\
Residual & 18.26 & $\mathbf{1 4}$ & 1.30 & & & \\
Lack of Fit & 18.26 & $\mathbf{1 0}$ & 1.83 & & & \\
Pure Error & $\mathbf{0 . 0 0 0}$ & $\mathbf{4}$ & $\mathbf{0 . 0 0 0}$ & & & \\
Cor Total & 75.39 & $\mathbf{2 9}$ & & & & \\
\hline
\end{tabular}

The analysis was done by means of fisher's "F"-test. The model F-Value was found to be 2.93 enlighten that the model is significant. The parameter are said to be significant if the F-Statistic probabilitty value is less than 0.05 . In this case $A^{2}, B^{2}, C^{2}, D^{2}, A C$ are statistically significant $(\mathrm{P}<0.05)$.

Furthermore, the relationship between the the predicted response from the empirical actual value and predicted value (Figure 5) show that the actual value are distributed relatively near the straight line, this proves that model is in agreement with the observed ones, indicating good fitness of the model.

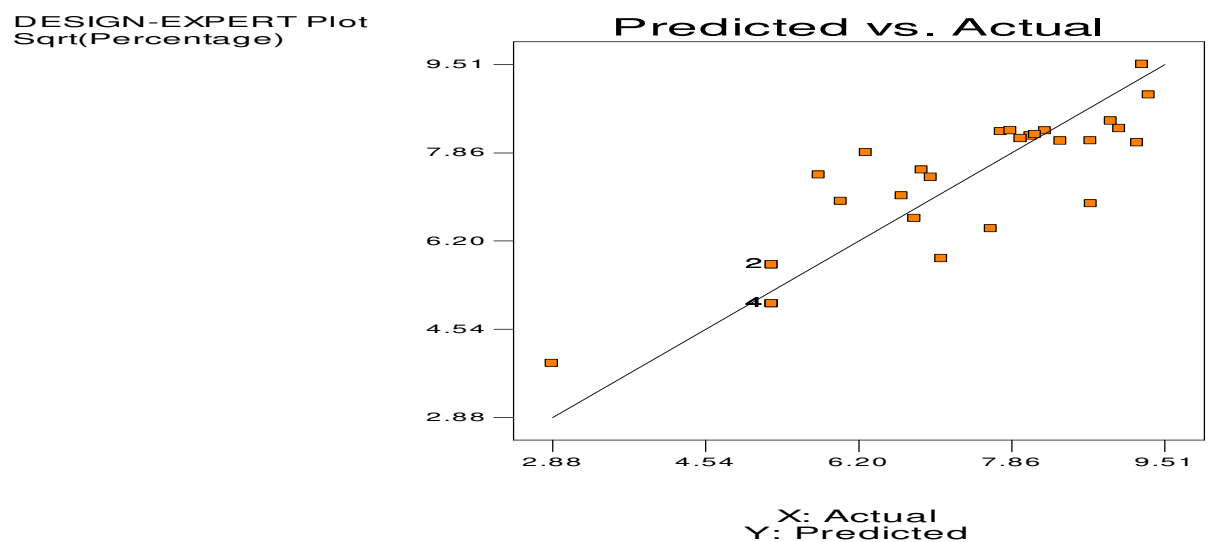

Figure 5: Observed $\mathrm{Cu}(\mathrm{II})$ removal versus predicted $\mathrm{Cu}(\mathrm{II})$ removal

\section{Adsorption Isotherms}

Adsorption isotherms are very important tools used in describing the stability of adsorbate at a fixed temperature and $\mathrm{pH}$. Adsorption units can be design and operated using the isotherm model, which describes the various behaviour of adsorption (Yang et al., 2011). The application of biosorption technique in the commercial scale requires proper quantification of the biosorption equilibrium. Equilibrium of an adsorption is reached whenever there is equal amount of ion adsorbed and desorbed. In this current study, the most frequently used adsorption isotherms, Langmuir and freudlich are been used. Biosorption of $\mathrm{Cu}$ (II) ions based on the values of the correlation coefficient $\left(R^{2}\right)$ was found to fit better with the Freudlich isotherm. 


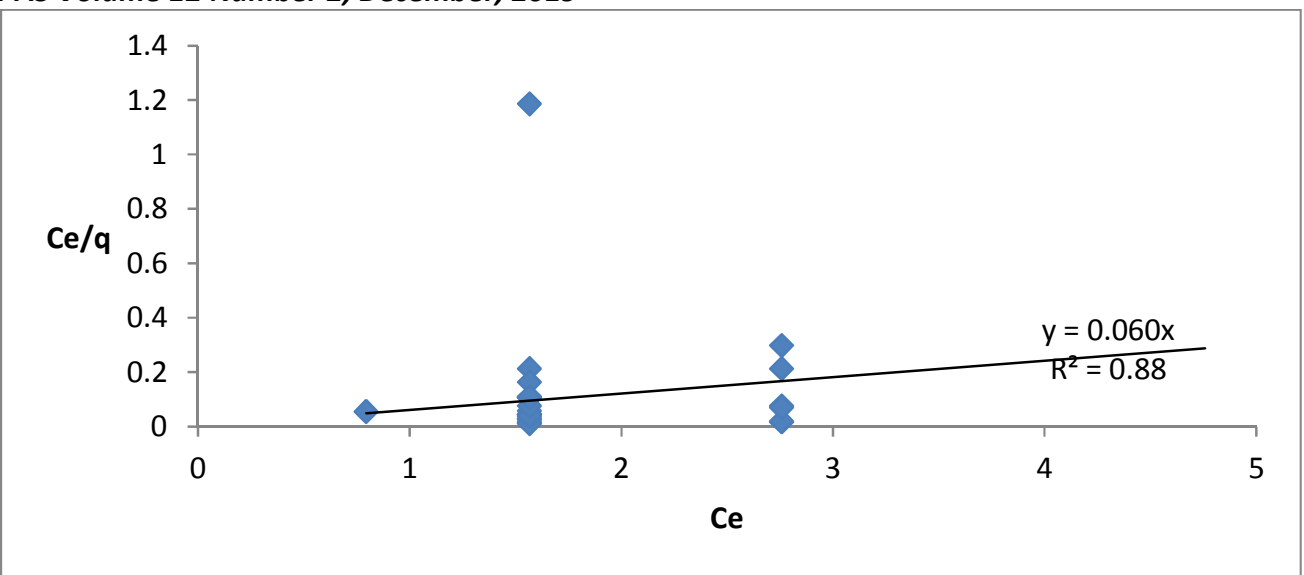

Figure 7: Langmuir plot of $\mathrm{Cu}$ (II) ion adsorption on NLP

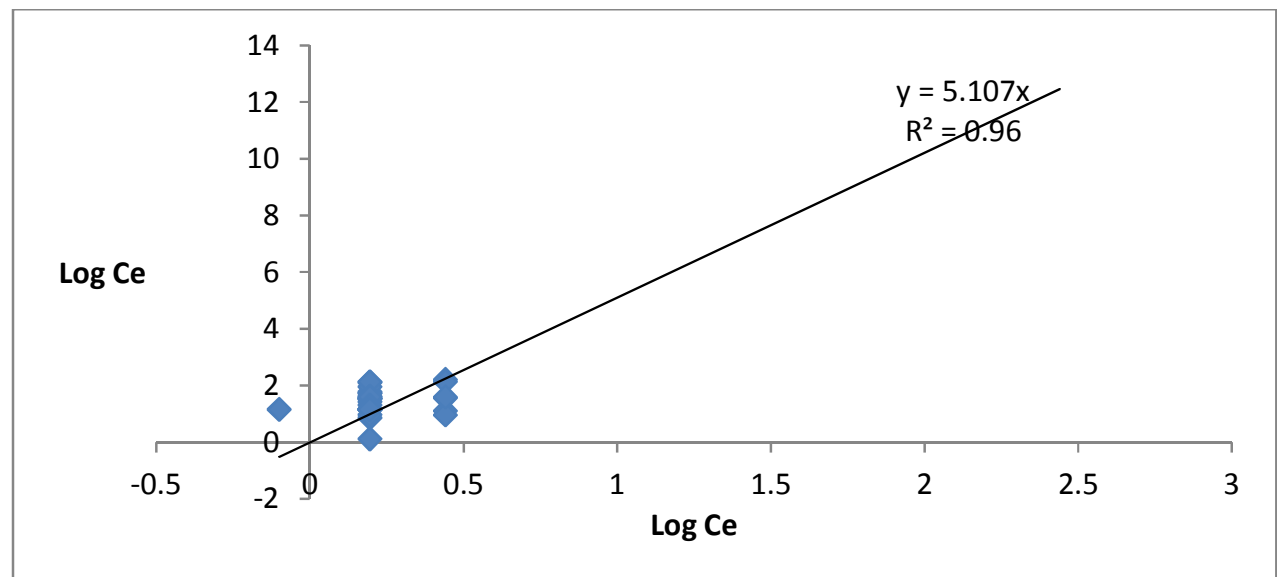

Figure 8: Freudlich plot of $\mathrm{Cu}$ (II) ion adsorption on NLP

\section{CONCLUSION}

The present investigation was carried to study the removal of $\mathrm{Cu}$ (II) from aqueous solution using adsorption over NLP and to conduct process optimisation using RSM for finding the optimum values of parameter affecting the process to achieve maximum removal efficiency. The study showed that NLP dose, contact time, contribute more to adsorption. The parameters were calculated using the experimental data. The experimental values

\section{REFERENCE}

Arami, M., Limaee, N.Y., Mahmoodi N.M and Tabrizi, N.S. (2006). Equilibrium and kinetics for the adsorption of direct and acid dyes from aqueous solution by soya meal hull. Journal of hazard materials. 135:171-179.

Ayhan, I. S. and Ozacar, M. (2008), Biosorption of $\mathrm{Cu}$ (II) from aqueous solutions by mimosa tanin gels. Journal of Hazardous Materials, 157: 277-285.

Basci, N., Erdem, K. and Beyhan, K. (2003).Biosorption of copper (II) from obtained were found to agree satisfactorily with the values predicted by the model. The optimal adsorption of copper was obtained as temperature, contact time and NLP dose and the values of these were found to be $308 \mathrm{~K}$, $97.5 \mathrm{~min}$ and $1.5 \mathrm{~g}$ respectively resulting in $100 \%$ of adsorption of copper. In this study we found the optimum operating condition for $\mathrm{Cu}$ (II) adsorption on NLP, which can be used for adsorption based water treatment process.

aqueous solutions by wheat shell. Desalination 164:135-140

Bajpai, S.K. and Jain, A. (2010).Removal of copper (II) from aqueous solution using spent tea leaves (STL) as a potential sorbent. Water $S A, 36$ (3).

Chafik,D., Bchitou, R. And Bouhaouss, A. (2014). Application of Box-Behnken Design for the removal of copper in aqueous solutions by phosphogypsum. J. Mater. Environ. Sci. 5:1605-1610

Das, B. (2017) Response surface modeling of copper (II) adsorption from aqueous solution onto neem (Azadirachta indica) 
BAJOPAS Volume 12 Number 2, December, 2019

bark powder: Central composite design approach. Journal of Materials and Environmental Sciences. 7: 2442-2454

Gupta, V. K., Rastogi, A., Saini, V. K. and Jain, N. (2006). Biosorption of Copper (II) from aqueous solutions by Spirogyra species. Journal of Colloid and Interface Science, 296: 59-63.

Hossain, S. M. And Anatharaman, N. (2005). Studies on Copper (II) biosorption using Thiobacillus ferrooxidans. Journal of the University of Chemical Technology and Metallurgy, 3:227-234

Ianisl, M., Tsekova, K. And Vasileva, S. (2006). Copper biosorption by Penicillium cyclopium. Equilibrium and modelling study. Biotechnology, 195.

Kumar Y. P., King, P. And Prasad, V.S.R.K. (2006). Zinc biosorption on tectona grandis leaves biomass: Eqauillibruim and kinetic studies. Chemical engineering journal. 12: 63-70.

Krishnani, K.K., Meng, X., Christodoulatos, C. and Boddu, V.M., (2008), Biosorption mechanism of nine different heavy metals onto biomatrix from rice husk, 153: $1222-1234$.

Montanher, S.F., Oliveira, E.A and Rollemberg N.C. (2005) Removal of metal ions from aqueous solutions by sorptions onto rice bran. Journal of hazard material, 117: 207-211

Ngah, W.S.N. and Hanafiah, M.A.K.M. (2008) Surface modification of rubber (Hevea brasiliensis) leaves for the adsorption of copperions: kinetic, thermodynamic and bindingmechanisms. Journal of Chem. Technol. Biotechnology, 84: 192-201

Öztürk, D. And Şahan, T. (2015) Design and Optimization of $\mathrm{Cu}(\mathrm{II})$ Adsorption Conditions from Aqueous Solutions by Low-Cost Adsorbent Pumice with Response Surface Methodology. Pol. J. Environ. Stud. 4: 1749-1756
Ozacar, V. K., Sengil, A. I., (2002) Adsorption of acid dyes from aqueous solutions by Calcined alunite and granular activated carbon. Adsorption, 8: 301-308.

Qi, B.C. and Aldrich, C. (2008). Biosorption of heavy metals from aqueous solutions with tobacco dust, Bioresource Technology, 99: 5595-5601.

Rathnakumar, S., Sheeja, R. Y. and Murugesan, T. (2009). Removal of Copper (II) from Aqueous Solutions Using Teak (Tectona grandis L.f) Leaves: World Academy of Science, Engineering and Technology 56

Sheng, P.X., Wee Y.P. and Chen J.P. (2008). Biosorption of copper by immobilised marine algal biomass. Chemical engineering journal, 136: 156-163.

Singh A., K. Kulkarni and A.D. Kulkarni (2017). Application of appopotite in adsorption of heavy metals ( $\mathrm{Co}$ and $\mathrm{Ni}$ ) from wastewater. Chemistry and materials research, 2: 16-21.

Sulaiman, M.S. and Garba, M.D.(2014). Biosorption Of $\mathrm{Cu}(\mathrm{II})$ Ions From Aqueous Solution Using Azadirachta indica (Neem) Leaf Powder. Chemical and Process Engineering Research 27: 2224-7467

Veglio, F., Beolchini, F. (1997). Removal of metals by biosorption: a review. Hydrometallurgy, 44: 301-16.

Yazici, H., Kilic, M. and Solak, M. (2008). Biosorption of copper (II) by Marrubium globosum subsp. Globosum leaves powder: Effect of chemical pretreatment. Journal of Hazard Mater, 151: $669-675$.

Yang, L., Brigitte H. and Harald H. (2011). Biosorption of $\mathrm{Cu}$ (II) Ions from Aqueous Solution by Red Alga (Palmaria Palmata) and Beer Draff. Materials Sciences and Applications, 2: 70-80. 